\title{
DIGITAL BUILDING DATA LONGEVITY AND INTEROPERABILITY CHALLENGES IN THE DOCUMENTATION OF HERITAGE BUILDINGS
}

\author{
A. Khalil ${ }^{1}$, S. Stravoravdis ${ }^{2}$ \\ ${ }^{1}$ University of Greenwich; A.Khalil@greenwich.ac.uk \\ ${ }^{2}$ University of Liverpool; S.Stravoravdis@liverpool.ac.uk
}

\section{Commission II}

\begin{abstract}
KEY WORDS: Digital Building Data, BIM, Data Longevity, Interoperability, Heritage Buildings, Digital Documentation
\end{abstract}
\begin{abstract}
:
One of the major motivations behind the introduction of BIM (Building Information Modelling) was to mitigate the challenges of interoperability and interdisciplinary interaction between different stakeholders, this is particularly critical in the heritage buildings sector that involves more diverse stakeholders in a wide range of disciplines compared to a standard construction project. A crucial concern in dealing with heritage buildings is the longevity and safeguarding of the digital documentation data that is usually required to be kept as a digital record for the future. This is especially challenging in the digital medium due to the diversity of the software tools, and the fast-advancing and changing software market.
\end{abstract}

In order to assess the needs and challenges facing the heritage buildings sector in terms of data longevity and interoperability and to assess the interdisciplinary interaction needs of relevant disciplines, the authors designed an online survey targeting professionals and academics in the heritage buildings sector and the wider AEC industries. This paper presents the preliminary findings of this survey.

\section{RELATED WORKS}

Prior to the era of BIM, a range of software and a variety of data formats have been used to describe data, such as CAD software and DWG, DXF, 3DS formats for managing 2D/3D geometric data, PDF for $2 \mathrm{D}$ and textual information, and many other formats for raster and vector graphical data, as well as charts and database formats. However, the interpretation of data formats into different software was rather limited and thus the integration of various disciplinary processes was restricted. These were among the primary motives for the development of the BIM concept.

BIM represents the potential to integrate and manage data from discrete sources within the same platform. However, many challenges arise in integrating such diverse data which is in and of itself a topic for research and development. Another challenge is in the usage of proprietary formats by BIM software developers which makes it more challenging to exchange data between software.

According to the UK Government \& Industry Interoperability Group (GIIG), interoperability is defined as the ability of two or more systems to exchange information securely and to use the information that has been exchanged. This exchange must not require additional processing, and must not be legally or technically restricted to specific software solutions (GIIG 2021). The European Interoperability Framework (EIF) categorises interoperability into technical interoperability, organisational interoperability, semantic interoperability and legal interoperability (National Interoperability Framework Observatory 2017). BIM interoperability refers to BIM applications' capabilities to share, exchange, gather, and process the same data via a common set of exchange formats, by using the same file formats and the same protocols (Grilo and JardimGoncalves 2010) (Shehzad et al. 2021). BIM interoperability enables model sharing and linking data between different operators, and BIM applications ensure data consistency (Tommasi and Achille 2017)
Interoperability limitations between different platforms has been identified as the main obstacle to adopting BIM by the market since 2010 (Grilo and Jardim-Goncalves 2010) and it still reported as such in more recent studies (Muller et al. 2017) (Shehzad et al. 2021).

While stakeholders involved in new built projects are somehow limited to typical teams of architects, engineers, contractors and facility managers, stakeholders involved in heritage projects can include, in addition to the above, a very wide range of disciplines such as archaeologists, historians, surveyors, conservators, various levels of government bodies, museum curators, public dissemination professionals, as well as many specialised contractors. Every discipline and team involved can potentially use their own specialised tools and software. This coupled with the fact that heritage projects are starting at an intermediate point in the asset's life cycle, which can be much more complex than the relatively straightforward cradle-to-grave model that describes new-build construction (Historic England 2017), which makes heritage projects usually unpredictable and new teams can join the project at any point in its lifetime. Due to this the heritage sector is in more need for an efficient interoperability practice. However, fewer research efforts are concerned with interoperability issues specifically within the heritage buildings sector. Thus, more research is needed to address the interoperability challenges of BIM environments to help enhance their ability for the integration of the diverse sources of data and the involvement of the various stakeholders that are crucial for the protection and survival of the built heritage.

Longevity of data is another important consideration as building data should be accessible throughout the lifecycle of the building from design to construction to operation. Many aspects can affect the longevity of building data. Beach et al. (2017) describe longevity as one of the main obstacles slowing the widespread adoption of BIM and they summarised the obstacles in: (1) lack of clarity as to who owns and is responsible for BIM, (2) fragmentation of BIM data across design and engineering teams and then the contractor and facilities management (FM) companies, and (3) information not being sustained across the life 
cycle of a building. On a technical basis, many factors can affect data longevity, but they are usually related to the fast-developing nature of the software market which results in the continuous emergence of new software and new proprietary formats, and the obsolescence of older software, which means that data cannot be interpreted in between software, consequently causing the loss of significant data created with outdated software. Moreover, even with the ongoing development of newer versions of the same software, there can still be issues with a loss of support for data created with older versions of the same software.

In the heritage buildings sector, challenges of longevity are even greater as - alongside the preservation of the building itself - the digital data of the building should also be preserved and accessed for a longer time to act as a record of the building and its alterations over its lifespans (Khalil, Stravoravdis, and Backes 2020). In fact, the data of the building should ideally outlive the building itself, to serve as an accurate representation and documentation of the building in case of any loss or damage of the building's fabric. This coupled with the short lifespan and high development rate of digital software, means that current documentation stored on current data formats are unlikely to be readily usable in future developed software, which clearly undermines the ability of BIM to be the medium for long term storage of heritage buildings documentation data. Therefore, the issues of data longevity and software obsolescence are usually much more prominent in the heritage sector than any other sector within the AEC industries. few studies discuss the issue of data longevity in the heritage sector, which represents a real challenge for the protection and storage of heritage buildings data.

\section{DEVELOPED METHODOLOGY}

In order to explore potential problems of digital data storage, reaccessibility and potential challenges of BIM data interoperability in the heritage sector and the wider AEC industries as well as exploring their different needs, the researchers designed an online questionnaire with the objectives of: (1) assessing the needs of both the general AEC industry and the heritage buildings sector for long term storage and reaccessibility, (2) exploring issues of interoperability of BIM data, (3) comparing BIM needs between heritage buildings sector practitioners and other practitioners in the AEC industry, (4) evaluating the need for interdisciplinarity and interoperability between distinct disciplines involved in the digital documentation of heritage buildings, (5) assessing the needs of accessing various data categories for different disciplines within the heritage sector.

The questionnaire is divided into three sections. The first section titled "General information" aims to categorise the participants into appropriate categories: first categorisation is to identify participants working in heritage buildings from other participants within the AEC industries, in order to isolate the heritage sector participants and study responses that are specific to the area, and to compare their responses to other AEC participants that are not working in heritage related projects (titled in the study "AEC participants"). The second categorisation is to identify participants working with BIM and participants not working with BIM (Figure 1). Also, within this section a question about work/research interests is aiming to associate participants with one or more of eight different groups: History/Archaeology, Geometry/Survey/Modelling, Education/Public dissemination, Design, Conservation, Engineering/Sustainability, Construction, and Management, in order to assess the variations in needs and challenges for each group.
The second section of the questionnaire titled "Digital data management" is asking questions about data storage, data reaccessibility and interoperability issues. The third section "Heritage Buildings Digital Documentation" is only relevant to participants identified as heritage sector participants.

The questionnaire was published online and invitations to participation were sent to various groups of different disciplines from both academic and professional backgrounds. The results of the survey will be discussed in the next section.

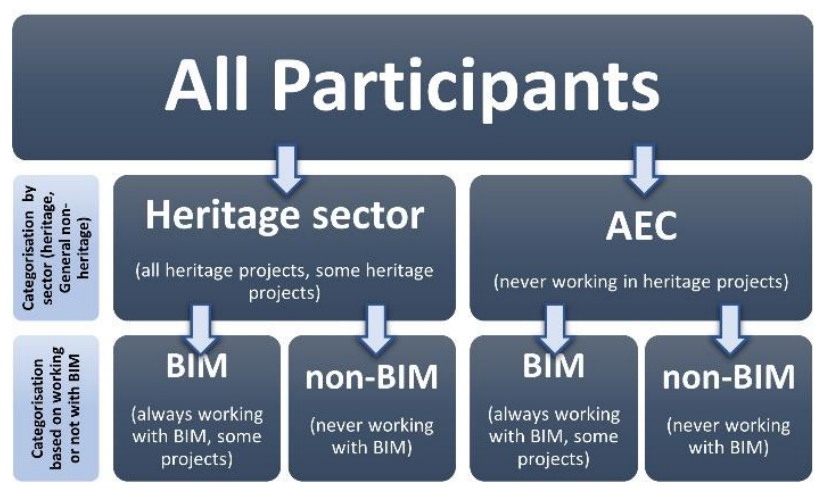

Figure 1: Categorisation of questionnaires participants.

\section{QUESTIONNAIRE RESPONSES}

The questionnaire received 82 responses from different disciplines. $45(55 \%)$ of the participants admitted they are fully or partially working in heritage projects and were identified in the study as "Heritage sector participants". The remaining 37 participants $(45 \%)$ responded they are not involved in any heritage related projects and are identified in the study as "AEC participants" (Figure 2). In a following question about using BIM in their projects, 48 (59\%) responded they use BIM in all or some of their projects in contrast to $34(41 \%)$ who said they never use BIM (Figure 3). There is some difference in BIM usage between heritage participants (53\%) and AEC participants (65\%) (Figure 4). Figure 5 presents the distribution of participants in both Heritage sector/AEC categorisation and BIM/non-BIM categorisation.

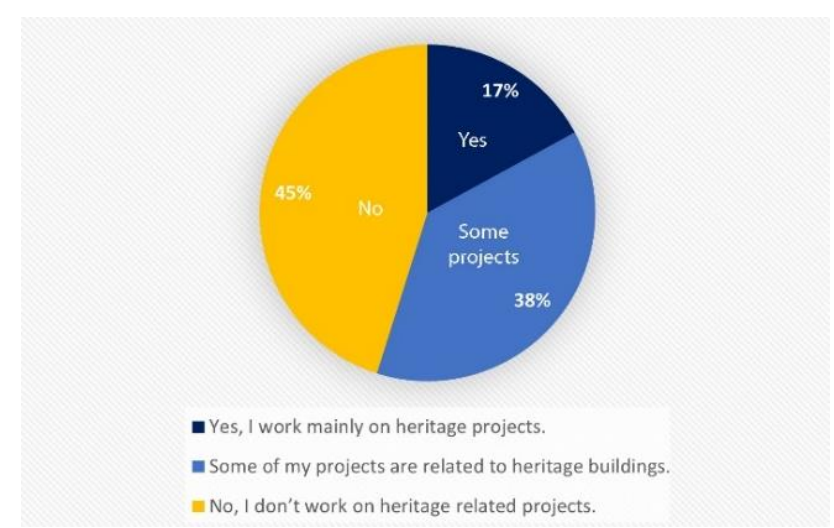

Figure 2: Responses of participants on whether they work in heritage related projects. 


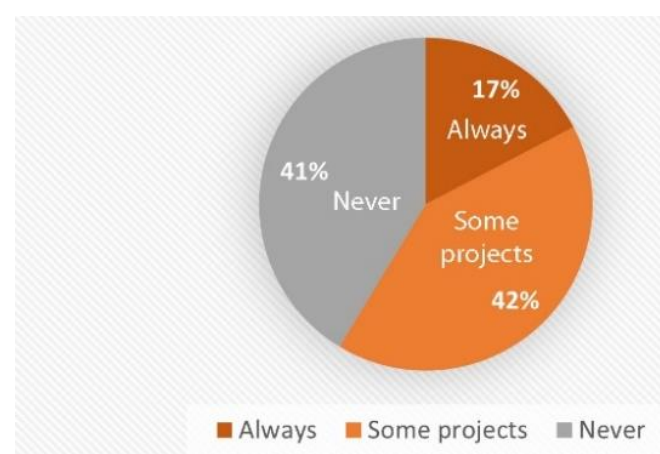

Figure 3: Responses of participants on whether they use BIM in their projects.

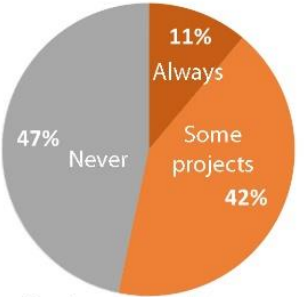

Heritage participants

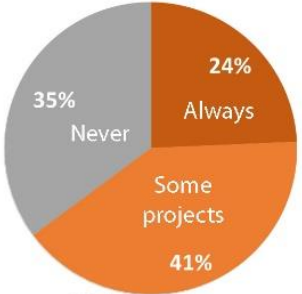

AEC participants
घAlways $\quad$ Some projects $\square$ Never

Figure 4: Responses of participants on whether they use BIM in their projects categorised by sector.

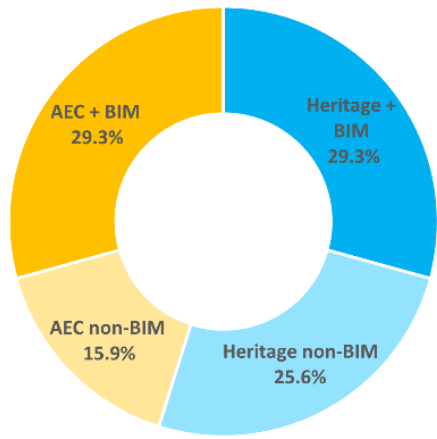

Horking with BIM

Heritage participants not working with BIM

AEC participants not working with BIM

II AEC participants working with BIM

Figure 5: Distribution of participants by heritage/AEC and the usage or not of BIM.

A question in the first section of the online survey was asking about work/research interests the participants are related to, they could choose as many options as relevant from a list containing 19 interests as well as an "other" option where they could add non-listed choices. In the analysis phase the responses were grouped into eight interest groups to study the differences between different disciplines within the heritage sector participants. The highest number of participants were associated with design (24 participant) followed by conservation (21 participant), Geometry/survey/modelling (20 participant), History/archaeology (19 participant), Engineering/sustainability (16 participant), Education/public dissemination (16 participant), Construction (14 participants), and the least group was Management with only 4 participants associated to it (Figure 6).

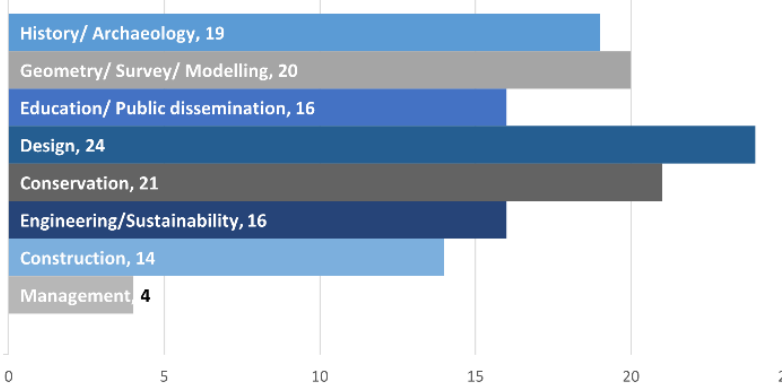

Figure 6: Number of heritage sector participants by interest groups.

\section{RESULTS}

This section will present the main results of the online survey followed by a discussion of the findings.

In order to assess the need for future re-accessibility of digital data, a question about whether the participants needed to reaccess their projects in the future (more than a year later) revealed that the heritage sector is in more need for long term data accessibility with $84.4 \%$ stated they need to access their digital data in the future compared to $64.9 \%$ of the general AEC participants (Figure 7). A follow-up question about the percentage of their projects that need future re-accessibility showed that $33.3 \%$ of the heritage participants need to access more than half of their projects in the future compared to $24.3 \%$ of the AEC participants (Figure 8). A similar question concerning BIM data re-accessibility demonstrated slightly lower numbers from both heritage and AEC participants with $75 \%$ and $58.3 \%$ respectively that need future re-accessibility of BIM data (Figure 9). The breakdown question for the percentage of BIM projects that need future re-accessibility showed similar percentage that need to re-access more than half of their projects in both the AEC sector and the heritage sector with about $20.8 \%$ of the responses in both categories (Figure 10).

\section{Do any of your projects require to be re- accessed after completion? (1+ years later)?}

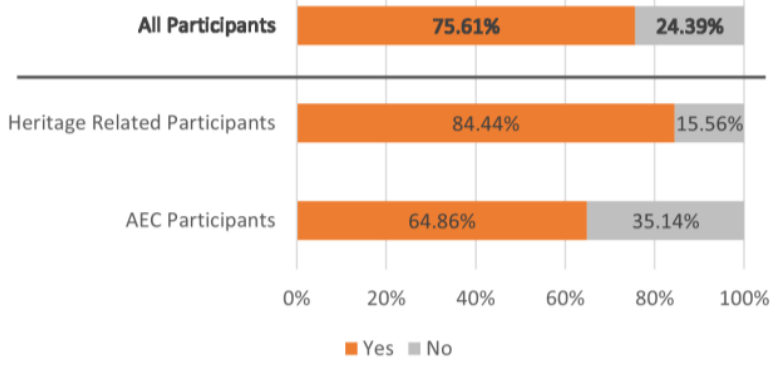

Figure 7: Need for future re-accessibility of digital data.

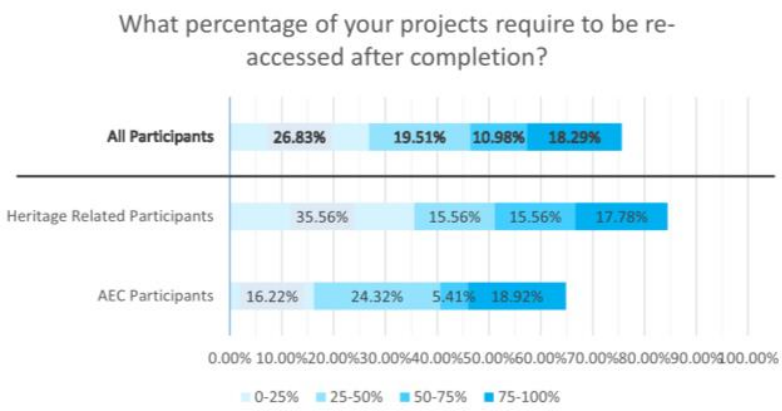

Figure 8: Percentage of projects that need future reaccessibility. 
Do any of your BIM projects require to be reaccessed after completion (1+ years later)?

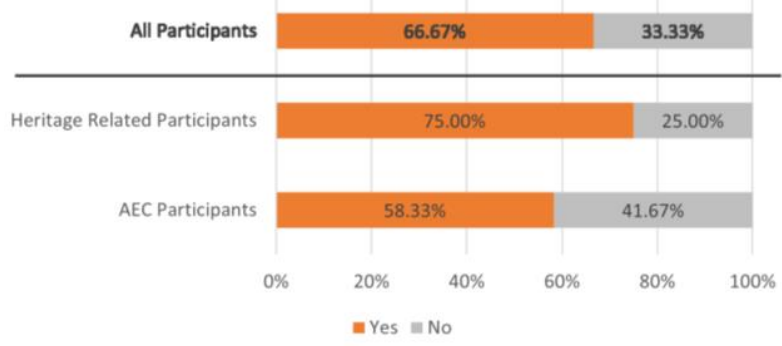

Figure 9: Need for future re-accessibility of BIM data.

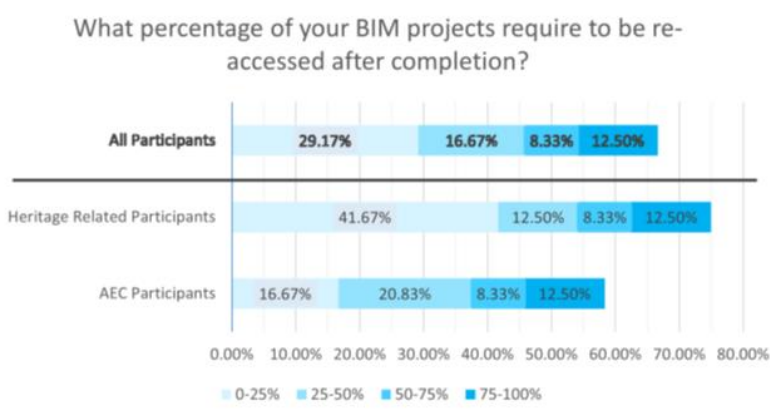

Figure 10: Percentage of BIM projects that need future reaccessibility.

In order to evaluate the need for data interoperability in heritage buildings sector, a set of questions for the heritage participants investigated this point. The first question is asking about their needs to collaborate with different disciplines, where 93\% approved, with 69\% stated that they often need such collaboration. The second question is about the need for digital data exchange where about $91 \%$ of the participants confirmed and $67 \%$ often needed data exchange. The third question was specific for BIM data exchange where $88 \%$ approved but only $42 \%$ said that they often need BIM data exchange (Figure 11).

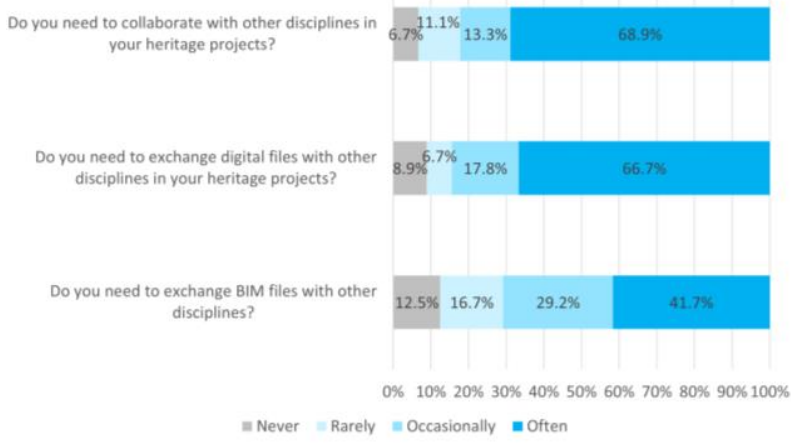

Figure 11: Responses of the heritage sector participants concerning their needs for collaboration with other disciplines, exchange of digital data and exchange of BIM data.

In response to a question for the heritage participants about whether they are involved in the phase of documentation of heritage buildings, $78 \%$ of the participants responded with yes (Figure 12). This showed the highest percentage in the conservation interest group (95\%) and the lowest in the construction group (71\%) (Figure 13).

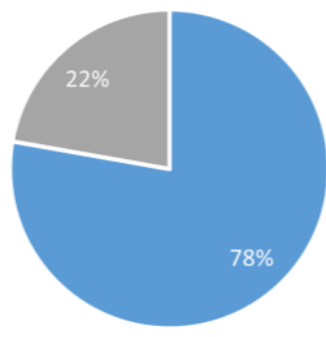

= Involved in the documentation of heritage buildings
= Not involved in the documentation of heritage buildings

Figure 12: Involvement in the phase of documentation of heritage buildings.

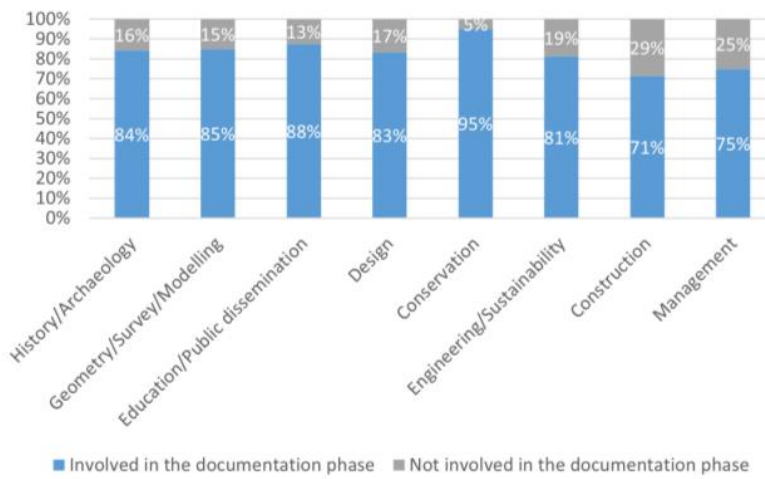

Figure 13: Involvement in the documentation phase by interest group.

Digital data concerning heritage buildings can be categorised into four distinctive categories: History/archaeology data, Geometric data, Pathologic data, and Performance data (Figure 14) (Khalil, Stravoravdis, and Backes 2020). One of the objectives of this online surveys is to study the variation in needs of the different disciplines for each data category. Graphs from Figure 14 to Figure 21 are colour coded by heritage data category to facilitate the graphs reading and interpretation: history/archaeology data is coded with shades of blue, geometric data is coded with shades of orange, pathologic data is coded with shades of yellow, and performance data is coded with shades of green.

A question in the online survey is asking heritage sector participants about data categories they consider essential for their work, $84 \%$ of the responses considered geometric data as one of their essential data, followed by archaeologic data for $62 \%$, performance data for $42 \%$ and pathologic data for only $24 \%$ of the participants (Figure 15). The breakdown of the responses of this question based on the different interest groups shows that the geometric data category is the highest needed data for every group except for the history/archaeology group, where the need for archaeologic data was slightly higher. The archaeologic data was the second needed data for geometry/survey/modelling group, education/public dissemination group, design group, conservation group, and management group. The pathologic data was needed for every group except the management group. The performance data was most needed for the engineering/sustainability and the construction groups (Figure 16). 


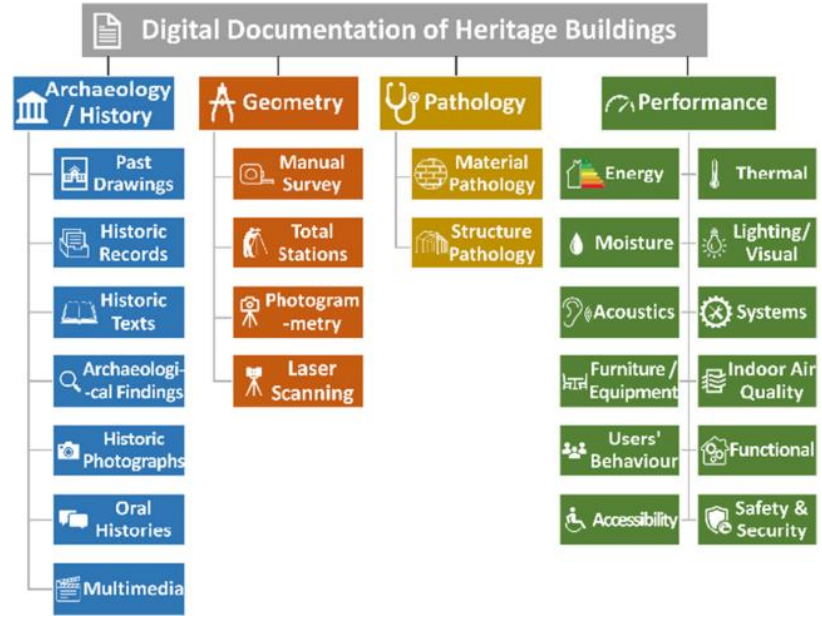

Figure 14: Data categories related to the documentation of heritage buildings (Khalil, Stravoravdis, and Backes 2020)

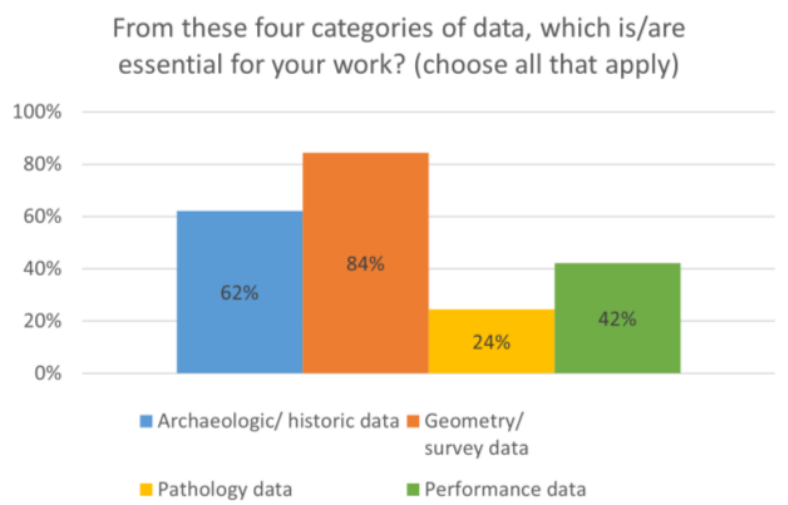

Figure 15: Responses of all the heritage sector participants for data categories they consider essential for their work.

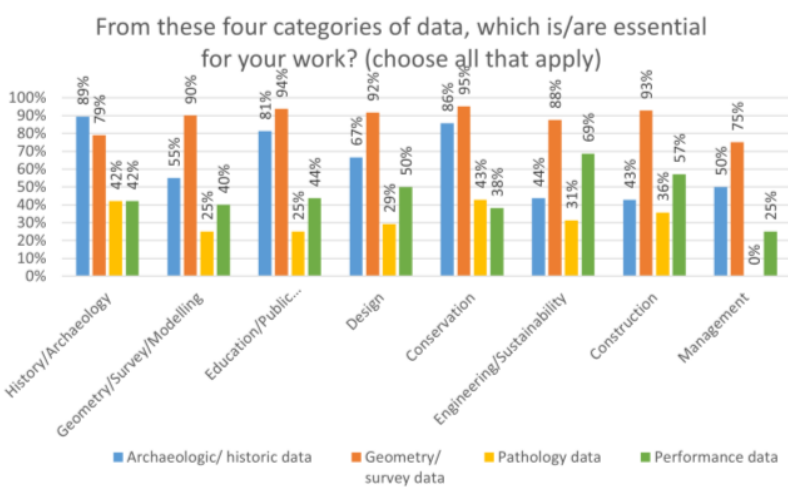

Figure 16: Responses of different interest groups for data categories they consider essential for their work.

For more details, a following question is asking participants to indicate in which capacity they need access to the different data categories using a scale of: never, rarely, occasionally, or often. The responses represented similar overall results with geometric data by far the most needed access to by any capacity (96\%) and the most often needed (69\%). Followed by the archaeologic data with overall needs of $84 \%$ and often needed $33 \%$, then the performance data $77 \%$ and $22 \%$ respectively, and finally the pathologic data overall needed by $62 \%$ of the participants and often needed by $11 \%$ (Figure 17).

This can be more emphasised in the breakdown of the responses concerning each data category by the different groups. The archaeological data category was more relevant to the history/archaeology group, conservation group and design group (Figure 18). Where geometric data was clearly highly relevant to all groups with at least $68 \%$ of the participants of each group often needed access to it (Figure 19). Pathologic data was most relevant to conservation and construction groups, followed by history, design and geometry groups (Figure 20). While the performance data was most relevant to engineering, construction, and conservation groups (Figure 21).

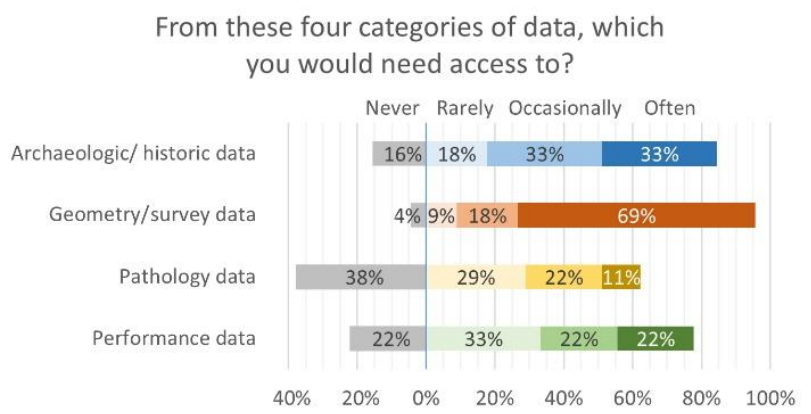

Figure 17: Responses of all heritage sector participants for data categories they need access to.

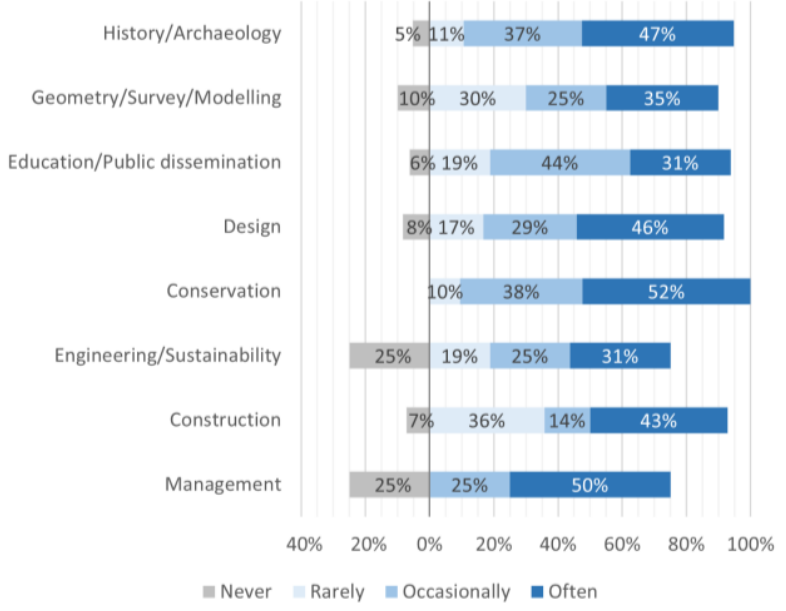

Figure 18: Access needed for archaeologic/historic data by the different groups.

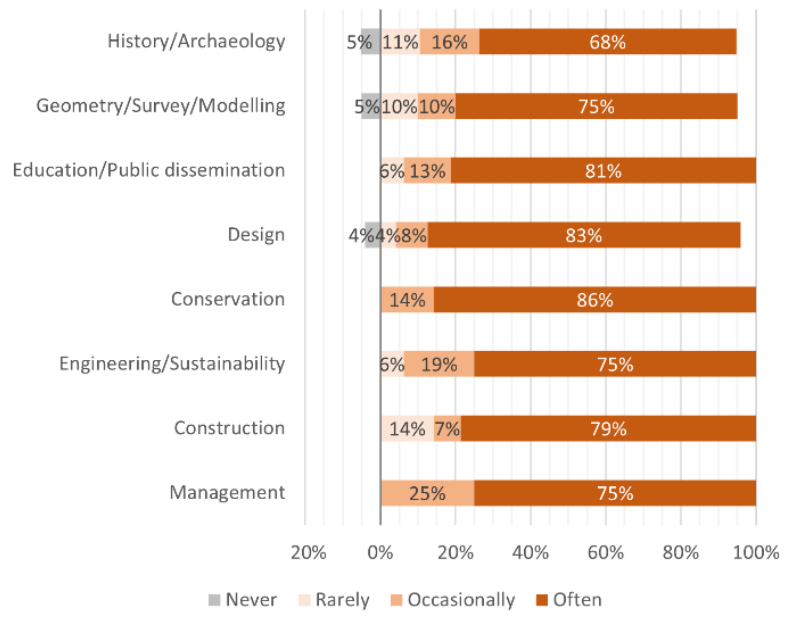

Figure 19: Access needed for geometric data by the different groups. 


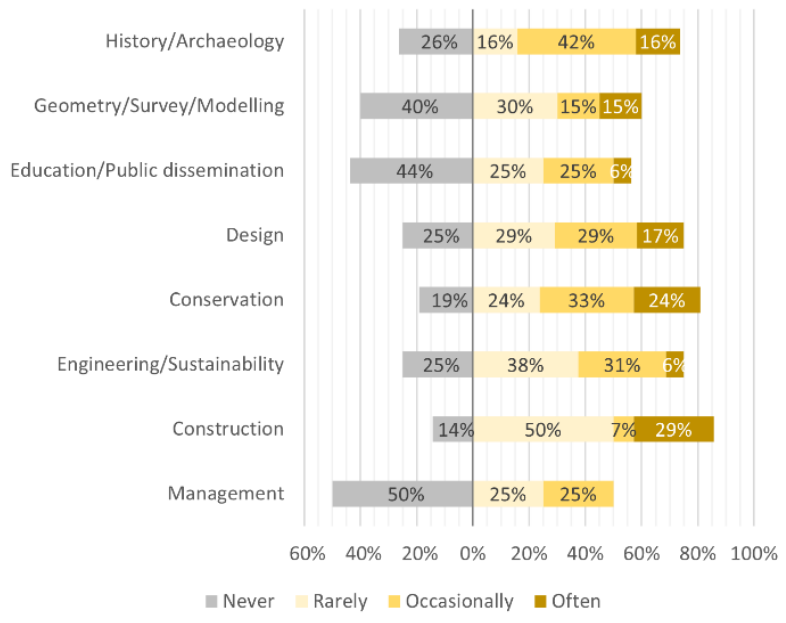

Figure 20: Access needed for pathologic data by the different groups.

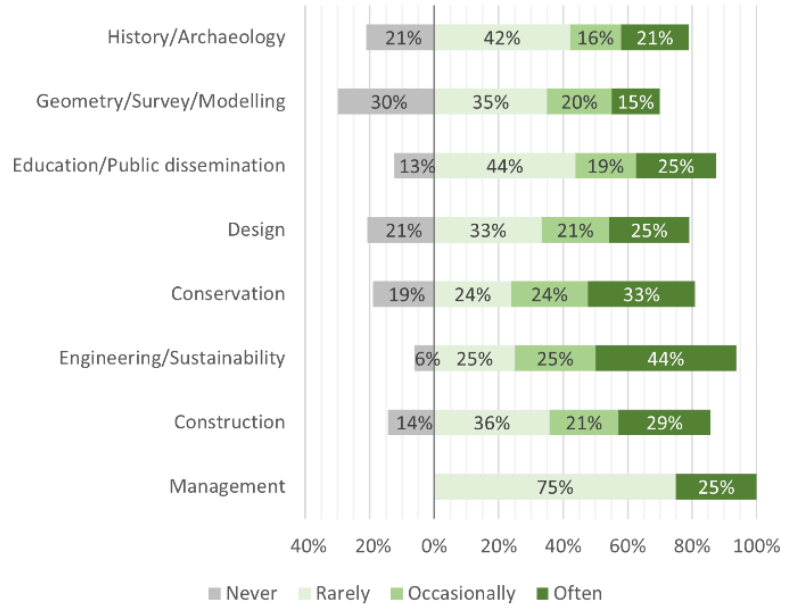

Figure 21: Access needed for performance data by the different groups.

\section{DISCUSSION}

Data longevity and interoperability are assumed to be more challenging for heritage buildings sector due to several factors including the nature of heritage projects that usually requires much wider interdisciplinary involvement and the value of the heritage building data that could be an asset to be preserved on its own. However, these assumptions required to be assessed and quantified in research. This online survey tried to answer these points.

The online survey is aiming to assess the data longevity needs for the heritage buildings sector and evaluate its urgency in comparison to the wider AEC industries. The responses showed higher needs of the heritage sector for future re-accessibility of digital data above $84 \%$ compared to $65 \%$ of AEC participants. However, BIM re-accessibility needs were less obvious with $75 \%$ in the heritage sector and $58 \%$ in the general AEC. This may suggest that BIM is still not trusted enough for some participants to keep as a long-term data record.

The survey results make it clear that interdisciplinary interaction is a crucial factor in heritage buildings sector with over $93 \%$ of the participants admitted that they require some level of collaboration with other disciplines in their heritage projects, including 69\% answered that they often rely on this collaboration. Data interoperability is similarly emphasised in the results of the questionnaire as $91 \%$ of the participants are in need of digital data exchange with other disciplines in some of their projects while two thirds of the participants admitted that they often need such digital data exchange. In terms of BIM data exchange, $88 \%$ acknowledged that they would need to exchange BIM data in some of their projects while only $42 \%$ addressed BIM data exchange as often required. This discrepancy between the digital data exchange requirements and the BIM data exchange requirements can be understood as a result of latency in BIM adoption in the heritage sector, as well as potential barriers in BIM interoperability. The latency of BIM adoption in heritage sector can also be observed in the comparison of BIM adoption in the questionnaire responses between heritage sector and AEC, as $53 \%$ of the heritage participants are using BIM in some capacity compared to $65 \%$ of the AEC participants.

Digital data related to heritage buildings can be put into four categories: archaeology/history data, geometry data, pathology data, and performance data. The need for different data categories can vary between the various disciplines involved in heritage projects (Khalil, Stravoravdis, and Backes 2020). One of the objectives of this online survey is to investigate these differences. In order to achieve this, participants were associated with one or more of eight groups of disciplinary interests: history/archaeology, geometry/survey/modelling, education/public dissemination, design, conservation, engineering/sustainability, construction, and management. The results suggest that the geometry data category is by far the most essential data by almost all the interest groups and the most data they needed access to. Archaeologic/historic data category was essential for the archaeology, education, design, and conservation groups. Adding to these groups, the geometry, and construction groups also showed that they would need access to archaeology/historic data in some of their projects. The pathologic data was most essential for archaeology, conservation, and construction groups, and was needed to be accessed also by design, and engineering groups. Performance data was essential for design, engineering, and construction groups. For the need to access, adding to the previous, management group also showed interest for performance data.

\section{CONCLUSIONS}

The survey results show that data longevity and interoperability challenges are very important issues in all of the AEC field, but they are even more prevalent in the heritage sector due to the nature of the heritage projects that require a collaboration of a wider range of disciplines and require long term data storage and re-accessibility. In order to address these challenges more research efforts are needed tailored to the needs of the heritage sector and for software developers to provide more robust solutions with their software and file formats. This in turn is likely to lead to a higher adoption of BIM within the heritage sector.

\section{REFERENCES}

Beach, Thomas, Ioan Petri, Yacine Rezgui, and Omer Rana. 2017. "Management of Collaborative BIM Data by Federating Distributed BIM Models." Journal of Computing in Civil Engineering 31 (4): 04017009. https://doi.org/10.1061/(asce)cp.1943-5487.0000657.

GIIG. 2021. "THE GIIG GLOSSARY GOVERNMENT \& INDUSTRY." https://www.cpni.gov.uk/informationinteroperability.

Grilo, António, and Ricardo Jardim-Goncalves. 2010. "Value 
Proposition on Interoperability of BIM and Collaborative Working Environments." Automation in Construction 19 (5): $522-30$. https://doi.org/10.1016/j.autcon.2009.11.003.

Historic England. 2017. "BIM for Heritage Developing a Historic Building Information Model." Swindon. https://historicengland.org.uk/advice/technicaladvice/recording-heritage/.

Khalil, Ahmed, Spyridon Stravoravdis, and Dietmar Backes. 2020. "Categorisation of Building Data in the Digital Documentation of Heritage Buildings." Applied Geomatics. https://doi.org/10.1007/s12518-020-00322-7.

Muller, Marina Figueiredo, Amanda Garbers, Filipe Esmanioto, Natan Huber, Eduardo Rocha Loures, and Osiris Canciglieri. 2017. "Data Interoperability Assessment Though IFC for BIM in Structural Design - a Five-Year Gap Analysis." Journal of Civil Engineering and Management $\quad 23 \quad$ (7): $243-54$. https://doi.org/10.3846/13923730.2017.1341850.

National Interoperability Framework Observatory. 2017. European Interoperability Framework. https://doi.org/10.2799/78681.

Shehzad, Hafiz Mohammad Faisal, Roliana Binti Ibrahim, Ahmad Fadhil Yusof, Khairul Anwar, Mohamed Khaidzir, Muhammad Iqbal, and Saad Razzaq. 2021. "The Role of Interoperability Dimensions in Building Information Modelling." Computers in Industry 129: 103444. https://doi.org/10.1016/j.compind.2021.103444.

Tommasi, C, and C Achille. 2017. "INTEROPERABILITY MATTER: LEVELS OF DATA SHARING, STARTING FROM A 3D INFORMATION MODELLING." https://doi.org/doi:10.5194/isprs-archives-XLII-2-W3623-2017. 